\title{
Time to quit that marathon running? Not quite yet!
}

\author{
Timothy Noakes
}

Received: 13 November 2013/Accepted: 13 November 2013/Published online: 3 December 2013

(C) Springer-Verlag Berlin Heidelberg 2013

The idea that marathon running might play a protective role specifically against coronary heart disease was first proposed by the Californian pathologist Thomas Bassler in the early 1970s. The Bassler hypothesis, so developed, proposed that anyone sufficiently trained to complete a $42 \mathrm{~km}$ marathon on foot would enjoy subsequent immunity from coronary atherosclerosis [1]. Our study showing the presence of coronary atherosclerosis in experienced marathon runners [4] relegated this theory to cardiomythology [7]. But simple case reports cannot address the more important question: does frequent marathon running enhance heart health? Or might it lead to long-term cardiac damage especially in those who continue to run such races in the $50 \mathrm{~s}$ and $60 \mathrm{~s}$ or at even older ages?

The studies of Möhlenkamp and colleagues [2] are amongst the first to address this more difficult research question. In an earlier study [2] they showed the presence of sub-clinical coronary artery disease in marathon runners, again disputing the Bassler hypothesis. Of greater concern was their finding that the degree of myocardial fibrosis in these runners was predicted by the number of marathons each had completed. This naturally raises the question: Are the demands of training for and completing many marathon races detrimental to cardiac health especially in persons with sub-clinical coronary artery disease?

As reported in this issue of the journal, to address this question Dr. Möhlenkamp and his colleagues [2] have now

This comment refers to the article available at doi:10.1007/s00395013-0391-8.

\section{T. Noakes $(\square)$}

Department of Human Biology, Sports Science Institute of SA, University of Cape Town, Boundary Road, Newlands,

Cape Town 7700, South Africa

e-mail: Timothy.noakes@uct.ac.za followed a group of 108 marathon runners for 6 years to determine predictors of medium-term outcome. The extent of the investigation is extremely comprehensive as all subjects underwent testing to determine Framingham Risk Score, coronary artery calcium (CAC) content and extent of myocardial fibrosis measured with magnetic resonance imaging-based late gadolinium enhancement. In addition, the response of high-sensitive serum troponin I to a marathon race was studied in a subset of 74 marathon runners. Medium-term outcomes in the marathon runners were compared with 864 age-matched, and 216 age- and risk factor-matched controls who had undergone the same intensive screening program. According to the bias that exercise is beneficial so that more exercise like marathon running is likely to be even more beneficial, one would expect that the marathon runners would have a superior outcome compared to both control groups of non-marathon runners.

Surprisingly, marathon runners had a similar cumulative 6-year cardiac event $(6 \%)$ rate as did the other two control groups $(5 \%)$. All-cause mortality was also not different between groups. Predictors of increased risk for future cardiac events in marathon runners included increased CAC scores and greater myocardial fibrosis.

This finding does not fit with the accepted belief that exercisers have improved cardiac health [6] and greater longevity [5]. It suggests either that the benefits of exercise are a parabolic rather than a linear function of the amount of exercise performed so that a threshold exists above which the beneficial effects are lost. Or else those persons who persist in running more than 20 marathons have other biological or psychological factors that act against good long-term cardiac health. The authors indeed acknowledge that their study population may not represent all marathon runners since their study "may have attracted runners who 
were concerned about their cardiac disease risk and had converted to a healthier lifestyle"; that is, that these athletes began marathon running after they perceived themselves to be at greater cardiac risk. Clearly more work is required to exclude this potential bias.

For those of us who have run more than our allotted 20 marathons, there is at least the assurance that our mediumterm outcomes are no worse than those of age- and risk factor-matched controls who have never run a marathon.

What is the individual marathon runner to take from this finding? Should the older amongst us immediately stop running all marathons and perhaps also other shorter distance races? In other words, how do these findings relate to the individual considered separate from the group? Here, the article again provides some interesting findings.

First, no cardiac events occurred during marathon races in line with the finding of low rates of sudden death or cardiac events during actual races. However, in four of seven runners who developed such events, some degree of physical activity triggered the event as we had noted previously [3]. The presence of premonitory symptoms that are frequently ignored may be an important factor explaining this relationship [3].

Second, $66 \%$ of runners over 50 years of age were at low risk for a future cardiac event so that there would be no logical reason to dissuade them from their choice to continue marathon running.

Third, the presence of high CAC scores predicts increased risk for cardiac events. Thus runners with high CAC scores, with or without myocardial fibrosis, should be targeted for advice about the desirability of their continued marathon running.

Perhaps the outstanding question raised by this study is the following: Why does exercise precipitate the cascade of events leading to an acute cardiac event particularly in those with sub-clinical coronary artery disease but who are committed to living a "healthy lifestyle"? What common factor, which cannot be prevented by regular exercise but which might even be triggered by physical activity, leads to both sub-clinical coronary artery disease and the triggering of a cardiac event?

What indeed might we be missing?

\section{References}

1. Bassler TJ (1977) Marathon running and immunity to atherosclerosis. Ann N Y Acad Sci 301:579-592. doi:10.1111/j.1749-6632. 1977.tb38231.x

2. Möhlenkamp S, Lehmann N, Breuckmann F, Brocker-Preuss M, Nassenstein K, Halle M, Budde T, Mann K, Barkhausen J, Heusch G, Jöckel KH, Erbel R (2008) Running: the risk of coronary events-prevalence and prognostic relevance of coronary atherosclerosis in marathon runners. Eur Heart J 29:1903-1910. doi:10. 1093/eurheartj/ehn163

3. Noakes TD (1987) Heart disease in marathon runners: a review. Med Sci Sports Exerc 19:187-194

4. Noakes TD, Opie LH, Rose AG, Kleynhans PH, Schepers NJ, Dowdeswell R (1979) Autopsy-proved coronary atherosclerosis in marathon runners. N Engl J Med 301:86-89. doi:10.1056/ NEJM197907123010205

5. Paffenbarger RS Jr, Hyde RT, Wing AL, Hsieh CC (1986) Physical activity, all-cause mortality, and longevity of college alumni. N Engl J Med 314:605-613. doi:10.1056/ NEJM198603063141003

6. Paffenbarger RS Jr, Wing AL, Hyde RT (1978) Physical activity as an index of heart attack risk in college alumni. Am J Epidemiol 108:161-175

7. Rennie D, Hollenberg NK (1979) Cardiomythology and marathons. N Engl J Med 301:103-104. doi:10.1056/ NEJM197907123010210 